\title{
The Impact of De novo Tumors after Liver Transplantation on Long Term Survival
}

Umberto Baccarani ${ }^{1 *}$, Diego Serraino², Gian Luigi Adani ${ }^{1}$, Anna Rossetto $^{1}$, Dario Lorenzin', Martina Gambato ${ }^{3}$, Andrea Buda ${ }^{3}$, Giacomo Zanus $^{4}$, Alessandro Vitale ${ }^{4}$, Pierluca Piselli ${ }^{5}$, Angela De Paoli ${ }^{2}$, Vittorio Bresadola ${ }^{1}$, Andrea Risaliti ${ }^{6}$, Pierluigi Toniutto ${ }^{1}$, Dino De Anna ${ }^{1}$, Umberto Cillo ${ }^{4}$ and Patrizia Burra ${ }^{3}$

${ }^{1}$ Department of Tissue \& Organ Transplantation University Hospital of Udine, Italy

${ }^{2}$ Epidemiology and Biostatistics Unit, Aviano Cancer Center, IRCCS, Italy

${ }^{3}$ Gastroenterology Section, Department of Surgical and Gastroenterological Sciences, University of Padova, Italy

${ }^{4}$ Hepato-Biliary and Liver Transplantation Unit, University of Padova, Italy

${ }^{5}$ Epidemiology Unit, INMI L. Spallanzani, IRCCS, Rome, Italy

${ }^{6}$ Hepato-Biliary and Transplantation Unit, University of Ancona, Italy

\begin{abstract}
Background and aims: the purpose of this study is to describe de novo post-liver transplant (LT) malignancies and compare their frequency with incidence rates from Italian cancer registries.

Methods: three hundred and thirteen patients subjected to LT, from 1991 to 2006, surviving 12 months and without diagnosis of previous cancer (including hepatocellular carcinoma), were evaluated for development of de novo malignancies excluding non-melanoma skin cancers

Results: during a total follow-up time of 1,753 person years (PYs), 40 (12.8\%) de novo malignancies were diagnosed in 40 recipients. The most common cancers were non-Hodgkin lymphoma (NHL) (20\%), cancer of the head and neck (17\%), Kaposi sarcoma (KS) (17\%) and esophageal tumors (12\%). The 1, 3, 5 and 10 years estimated survival were $70 \%, 56 \%, 48 \%$ and $39 \%$. Patients with de novo cancers had a lower 10 years survival $(p=0.0047)$ than patients without (39\% vs $75 \%$ ). The risk of cancer after LT was 3-fold higher than that of the general population of the same age and sex (95\% Cl:2.0-4.3). De novo tumor sites or types with significantly elevated standardized incidence ratio (SIR) included KS (SIR=212), $\mathrm{NHL}(\mathrm{SIR}=13.7)$, oesophagus ( $\mathrm{SIR}=18.7)$, melanoma $(\mathrm{SIR}=10.1)$ and head and neck cancers $(\mathrm{SIR}=4.6)$.
\end{abstract}

Conclusion: tumors after LT are associated with lower long-term survival, confirming that cancer is a major cause of late mortality.

Keywords: De novo tumor; Immunosuppression; Liver transplantation; Tumor after transplantation

\section{Introduction}

Liver transplantation is the treatment of choice for end-stage liver diseases, as it is demonstrated by the excellent long term survival after this procedure [1]. However, due to the need for immunosuppression, a high price should be paid for the improvement of life expectancy of those patients in terms of many serious complications, such as increased risk and tendency of developing infection and post-transplant malignancies [2]. An increased incidence of de novo post-transplant malignancies in immunosuppressed organ transplant recipients was first predicted by Starzl in 1968 [3] and since then the Israel Penn Transplant Tumor Registry (formerly the Cincinnati Transplant Tumor Registry), a voluntaristic registry collecting all the information on transplant recipients with de novo post-transplant cancers, has received data from 7,796 malignancies occurring in 7,316 recipients of solid organ transplantation of whom 269 liver transplant recipients with de novo post-transplant cancer [4]. The incidence of de novo neoplasm excluding non-melanoma skin cancers after liver transplantation ranges from $3 \%$ to $16 \%$, significantly higher than that observed in the general population [5], causing $25 \%$ of the deaths in patients who have survived more than 3 years after liver transplantation [6]. The aim of this study is to describe the incidence, epidemiology, characteristics and outcome of de novo post-liver transplant tumors, excluding nonmelanoma skin cancers, occurring in two liver transplant centers located in the north east part of Italy and to compare it with incidence rates from Italian cancer registries.

\section{Patients and Methods}

A total of 313 patients who underwent deceased donor LT, from
1991 up to 2006, at two liver transplant centers located in the north east part of Italy (182 in Udine and 131 in Padova), surviving at least 12 months from the transplant procedure and without diagnosis of previous cancer (including hepatocellular carcinoma), were evaluated by retrospective charts review for the development of de novo posttransplant malignancies, including melanoma and excluding the other skin cancers. Records of these patients were reviewed, and data on age at the time of transplant, indication for transplantation, interval from transplantation to diagnosis of malignancy, factors predisposing to the development of malignancy, treatment of malignancy, immunosuppression regimen, area of birth and residency at the time of transplantation and survival from the time of diagnosis of the de novo malignancies were collected. The immunosuppression regimen consisted of calcineurin inhibitors (cyclosporine or tacrolimus) in combination with steroids with or without azathioprine or mycophenolate. Immunosuppressive dosages before the development of the de novo tumors were indicated to maintain desired blood levels (tacrolimus 5 to $15 \mathrm{ng} / \mathrm{mL}$; cyclosporine 100 to $350 \mathrm{ng} / \mathrm{mL}$ )

*Corresponding author: Umberto Baccarani, MD, PhD, FEBS, Departmen of Surgery \& Transplantation Unit University Hospital Udine, P.le S.M. della Misericordia 1, II floor Pad. Petracco, 33100 Udine, Italy, Tel. +39-0432-559902 Fax: +39-0432-559-552; E-mail: umberto.baccarani@uniud.it

Received August 30, 2011; Accepted December 05, 2011; Published December 10, 2011

Citation: Baccarani U, Serraino D, Adani GL, Rossetto A, Lorenzin D, et al. (2011) The Impact of De novo Tumors after Liver Transplantation on Long Term Survival. J Transplant Technol Res S1:005. doi:10.4172/2161-0991.S1-005

Copyright: (c) 2011 Baccarani U, et al. This is an open-access article distributed under the terms of the Creative Commons Attribution License, which permits unrestricted use, distribution, and reproduction in any medium, provided the original author and source are credited. 
during follow-up and were modified after the diagnosis of the de novo tumors with the same schedule in the two LT centers. The diagnosis of malignancy was always established by histological examination of biopsies or surgical specimens of the tumour. The date of the biopsy or of the surgical procedure were designated as the date of cancer diagnosed. Patients were examined, including liver function tests and routine blood tests, every 3 months for the first year, every 6 months from the second to the fourth year, and then annually after transplantation in both LT centers. Person-years (PYs) at risk for cancer were computed from 30 days after enrolment (i.e., the date of transplant) to the date of last follow-up visit, or to the date of cancer diagnosis, or to the date of death. Observed cancers were the incident cases diagnosed during the study period and cancer diagnoses recorded during the follow-up visits were histologically confirmed and coded according to the International Classification of Diseases and Related Health Problems, $10^{\text {th }}$ revision (ICD-10). To avoid follow-up losses, information on cancer and on vital status was actively elicited either from clinical records, cancer registries (when available), or the census bureau of the town of residence. Multiple primary cancers were separately considered in the statistical analysis. Non-melanoma skin cancers in-situ and pre-neoplastic lesions were not included in the present analysis as i) information on basal cell carcinoma was not recorded, and ii) the report of squamous cell carcinoma might not have been complete. The number of observed incident cancer cases was compared to the expected number. This was computed from sex- and age-specific incidence rates from Italian cancer registries [7]. Standardized incidence ratios (SIRs) were computed dividing the number of observed cases by the number of expected ones. Ninety five percent confidence intervals (CIs) of SIRs were determined using the Poisson distribution [8]. Analysis of estimated survival was done with the Kaplan-Meier survival curves and log-rank test was done for comparison (SPSS 9.0.0 for Windows); a p-value less than 0.05 was considered significant.

\section{Results}

A total of 313 liver transplant recipients were analyzed for the development of de novo tumors covering a time period of 15 years (1991-2006). This cohort resulted from two liver transplant centers (Udine and Padova) located in the north east part of Italy; 182 patients were transplanted in Udine and 131 in Padova. The median age at transplantation of the 313 transplant recipients herein investigated (219 males and 94 females) was 51 years (range 44-57) with no differences between the two LT centers, while variations in their distribution according to calendar year at transplantation were due to differences in starting of liver transplant program in the two hospitals (Table 1).

Most of our study group was born (59.4\%) or resided (70.6\%) in northern Italy: during a total follow-up time of 1,753 PYs, $40(12.8 \%)$ de novo malignancies were diagnosed in 40 recipients of LT; there were 10 females and 30 males with a median age at the diagnosis of de novo tumor of 58 years old (range 44-69); 15 (8.2\%) were diagnosed in the cohort from Udine and $25(19 \%)$ in the cohort from Padova, the median follow-up was respectively 4.3 years (1.3-6.6) and 8.2 years (4.2-10.6) in the centers of Udine and Padova. The median time from transplantation to diagnosis of all type of de novo cancer was 54 months (range 2-245 months) and was not different between solid organ tumors 52 months (range 2-245 months) versus post-transplant lymphoproliferative disease (PTLD) 66 months (range 12-106 months) ( $\mathrm{p}=0.73$ ), solid organ tumors vs Kaposi sarcoma 25 months (range

\begin{tabular}{|c|c|c|c|c|c|c|}
\hline \multirow[b]{2}{*}{ Characteristics } & \multicolumn{2}{|r|}{ Total } & \multicolumn{2}{|r|}{ Padova } & \multicolumn{2}{|r|}{ Udine } \\
\hline & $\mathbf{N}$ & $(\%)$ & $\mathbf{N}$ & $(\%)$ & $\mathbf{N}$ & $(\%)$ \\
\hline Total & 313 & $(100)$ & 131 & $(100)$ & 182 & $(100)$ \\
\hline \multicolumn{7}{|l|}{ Gender } \\
\hline Females & 94 & $(30.0)$ & 35 & $(26.7)$ & 59 & $(32.4)$ \\
\hline Males & 219 & $(70.0)$ & 96 & $(73.3)$ & 123 & $(67.6)$ \\
\hline \multicolumn{7}{|c|}{ Age at transplantation (years) } \\
\hline Median (IQR) & 51.3 & $(44.4-57.1)$ & 47.3 & $(37.3-54.3)$ & 53.3 & $(47.4-58.4)$ \\
\hline$<35$ & 32 & $(10.2)$ & 27 & $(20.6)$ & 5 & $(2.8)$ \\
\hline $35-49$ & 109 & $(34.8)$ & 51 & $(38.9)$ & 58 & (31.9) \\
\hline$\geq 50$ & 172 & $(55.0)$ & 53 & $(40.5)$ & 119 & $(65.4)$ \\
\hline \multicolumn{7}{|c|}{ Calendar year at transplantation } \\
\hline 1991-1995 & 77 & $(24.6)$ & 77 & $(58.8)$ & & 0 \\
\hline$\geq 1996$ & 236 & $(75.4)$ & 54 & $(41.2)$ & 182 & $(100.0)$ \\
\hline \multicolumn{7}{|l|}{ Area of birth } \\
\hline Northern Italy & 186 & $(59.4)$ & 68 & $(51.9)$ & 118 & $(64.8)$ \\
\hline Central Italy & 21 & $(6.7)$ & 13 & $(9.9)$ & 8 & $(4.4)$ \\
\hline Southern Italy & 92 & $(29.4)$ & 47 & $(35.9)$ & 45 & $(24.7)$ \\
\hline Abroad & 14 & $(4.5)$ & 3 & $(2.3)$ & 11 & $(6.0)$ \\
\hline \multicolumn{7}{|l|}{ Area of residence } \\
\hline Northern Italy & 221 & $(70.6)$ & 75 & $(57.3)$ & 146 & $(80.2)$ \\
\hline Central Italy & 18 & $(5.8)$ & 13 & $(9.9)$ & 5 & $(2.8)$ \\
\hline Southern Italy & 72 & $(23.0)$ & 42 & $(32.1)$ & 30 & (16.5) \\
\hline Abroad & 2 & $(0.6)$ & 1 & $(0.8)$ & 1 & $(0.6)$ \\
\hline \multicolumn{7}{|c|}{ Transplantation centre } \\
\hline Padova & 131 & (41.9) & & & & \\
\hline Udine & 182 & $(58.2)$ & & & & \\
\hline \multicolumn{7}{|c|}{ Follow-up time (years) } \\
\hline Total & & 1,753 & & 985 & & 768 \\
\hline Median (IQR) & 5.8 & $(1.8-8.5)$ & 8.2 & $(4.2-10.6)$ & 4.3 & $(1.3-6.6)$ \\
\hline
\end{tabular}

Table 1: Characteristics of 313 patients who underwent liver_transplantation. 
3-67 months) ( $\mathrm{p}=0.13$ ) and PTLD vs Kaposi ( $\mathrm{p}=0.09)$. The type, characteristics and outcome of the 40 patients with de novo tumors are detailed in Table 2. The cumulative hazard of developing any type of $d e$ novo tumors included in this study is reported in Figure 1.

The most common type of de novo tumors diagnosed was PTLD (non-Hodgkin lymphoma) in $20 \%$ of cases, followed by cancer of the head and neck (17\%), Kaposi sarcoma (17\%), esophageal tumors (12\%), lung cancer (10\%), gastric adenocarcinoma (7\%), colon, melanoma and cervix cancer (5\% each) and breast tumor (2\%). Eighty-seven percent of patients diagnosed with head \& neck or upper gastrointestinal tumors have had the liver transplant for alcoholic liver disease; also 3 of 4 lung cancers had a history of smoking before LT continuing also after the transplant. Conversely, 6 out of $8(75 \%)$ patients diagnosed with de novo PTLD were HCV positive and the remaining 2 were HBV positive; overall all the patients diagnosed with de novo PTLD were transplanted for viral cirrhosis.

Twenty-two out of 40 (55\%) patients with de novo tumors died for causes related to their cancer; this mortality was higher for lung tumor (100\%), followed by esophageal and gastric cancer (62.5\%), tumor of the head and neck (57\%), Kaposi sarcoma and lymphoproliferative disease (50\% each). Mortality due to solid tumor and melanoma, was $58 \%$ (15 out of 26) and for Kaposi sarcoma and lymphoproliferative disease was $50 \%$ ( 7 out of 14 ). The $1,3,5$ and 10 years estimated survival were respectively $70 \%, 56 \%, 48 \%$ and $39 \%$ for all types of de novo tumors, with a median survival of 54 months (Figure 2). The 1, 3 and 5 years estimated survival was not different between solid tumors and

\begin{tabular}{|c|c|c|c|c|c|c|c|c|}
\hline Patient No & De novo tumor & Liver disease & Sex & IMS & $\begin{array}{l}\text { Time from OLT to } \\
\text { malignancy (months) }\end{array}$ & Treatment & Outcome & $\begin{array}{l}\text { Post-Tumor } \\
\text { Follow-Up } \\
\text { (months) }\end{array}$ \\
\hline 1 & Esophagus & ALD & $\mathrm{F}$ & СуA & 57 & surgery & alive $\mathrm{nf}$ & 122 \\
\hline 2 & Esophagus & ALD & M & СуА & 49 & $\mathrm{rt}+\mathrm{cht}+$ palliation & died $\mathrm{nr}$ & 13 \\
\hline 3 & Esophagus & ALD & M & СуА & 84 & surgery + rt + cht & alive $\mathrm{nf}$ & 83 \\
\hline 4 & Esophagus & ALD & M & FK & 66 & palliation & died $\mathrm{nr}$ & 5 \\
\hline 5 & Esophagus & ALD & $M$ & CyA & 45 & palliation & died $\mathrm{nr}$ & 15 \\
\hline 6 & Neck & ALD & M & СУА & 146 & surgery & alive $\mathrm{nf}$ & 18 \\
\hline 7 & Larynx & ALD & $\mathrm{F}$ & CyA & 6 & surgery $+r t$ & died $n r$ & 139 \\
\hline 8 & Salivary gland & ALD & M & СУА & 2 & surgery $+\mathrm{rt}$ & alive $\mathrm{nf}$ & 132 \\
\hline 9 & Larynx & $\mathrm{HCV} / \mathrm{HBV}$ & M & СуA & 98 & palliation & died $\mathrm{nr}$ & 7 \\
\hline 10 & Tongue & ALD & M & СуА & 19 & surgery & died $\mathrm{nr}$ & 5 \\
\hline 11 & Tongue & ALD & M & FK & 13 & surgery + rt & alive $\mathrm{nf}$ & 99 \\
\hline 12 & Pharyngeal & ALD & $\mathrm{F}$ & СуА & 131 & palliation & died $\mathrm{nr}$ & 1 \\
\hline 13 & Stomach & ALD & M & СуА & 49 & surgery & died $\mathrm{nr}$ & 4 \\
\hline 14 & Stomach & HBV & M & FK & 77 & surgery + rt + cht & alive $\mathrm{nf}$ & 39 \\
\hline 15 & Stomach & ALD & $M$ & FK & 53 & surgery & died $\mathrm{nr}$ & 1 \\
\hline 16 & Lung & $\mathrm{HCV} / \mathrm{HBV}$ & $M$ & СуA & 133 & surgery & died $n r$ & 3 \\
\hline 17 & Lung & PLD & M & FK & 13 & $\mathrm{rt}+\mathrm{cht}$ & died $\mathrm{nr}$ & 2 \\
\hline 18 & Lung & PSC & $M$ & FK & 34 & cht & died $\mathrm{nr}$ & 29 \\
\hline 19 & Lung & ALD & $M$ & FK & 21 & cht & died $\mathrm{nr}$ & 10 \\
\hline 20 & Colon & HBV & M & СУА & 159 & surgery & died $\mathrm{nr}$ & 10 \\
\hline 21 & Colon & PSC-HCV & $M$ & СуA & 133 & surgery + cht & alive $\mathrm{nf}$ & 30 \\
\hline 22 & Melanoma & ALD & $M$ & СУА & 97 & surgery & alive $n f$ & 20 \\
\hline 23 & Melanoma & $\mathrm{HCV} / \mathrm{HBV}$ & $\mathrm{F}$ & FK & 15 & surgery + ifn & alive $n f$ & 71 \\
\hline 24 & Cervix & ALD & $\mathrm{F}$ & СуA & 84 & surgery+rt & alive $\mathrm{nf}$ & 84 \\
\hline 25 & Cervix & $\mathrm{HCV}$ & $\mathrm{F}$ & СУА & 11 & surgery & died $\mathrm{nr}$ & 16 \\
\hline 26 & Breast & PBC & $\mathrm{F}$ & $\mathrm{FK}$ & 13 & surgery & alive $\mathrm{nf}$ & 94 \\
\hline 27 & Kaposi & HBV-HDV & M & СуA & 13 & surgery & died $\mathrm{nr}$ & 54 \\
\hline 28 & Kaposi & HBV & $M$ & FK & 36 & surgery & died $\mathrm{nr}$ & 93 \\
\hline 29 & Kaposi & HBV & M & FK & 133 & surgery & alive $\mathrm{nf}$ & 7 \\
\hline 30 & Kaposi & SSC & M & СуA & 56 & surgery & died $\mathrm{nr}$ & 40 \\
\hline 31 & Kaposi & ALD & M & СуА & 5 & reduction IMS & alive wn & 108 \\
\hline 32 & Kaposi & $\mathrm{HCV}$ & $\mathrm{F}$ & $\mathrm{FK}$ & 3 & surgery & alive $\mathrm{nf}$ & 94 \\
\hline 33 & PTLD & HBV & M & СуA & 72 & surgery cht & died $\mathrm{nr}$ & 64 \\
\hline 34 & PTLD & PSC-HCV & $\mathrm{F}$ & СУА & 66 & surgery cht & died $\mathrm{nr}$ & 13 \\
\hline 35 & PTLD & $\mathrm{HCV}$ & M & FK & 36 & cht & alive $\mathrm{nf}$ & 32 \\
\hline 36 & PTLD & HCV-HBV & M & FK & 58 & cht+rt & alive $\mathrm{nf}$ & 44 \\
\hline 37 & PTLD & HCV & M & FK & 101 & cht & died $\mathrm{nr}$ & 3 \\
\hline 38 & PTLD & HBV & M & CyA & 12 & cht+rituximab & alive $\mathrm{nf}$ & 24 \\
\hline 39 & PTLD & $\mathrm{HCV}$ & $\mathrm{F}$ & FK & 106 & cht & alive $\mathrm{nf}$ & 16 \\
\hline 40 & PTLD & $\mathrm{HCV}$ & $M$ & FK & 80 & palliation & died $\mathrm{nr}$ & 0 \\
\hline
\end{tabular}

ALD: Alcoholic Liver Disease; PSC: Primary Sclerosing Cholangitis; PBC: Primary Biliary Cirrhosis; PLD: Polycystic Liver Disease; SSC: Secondary Sclerosing Cholangitis nf: neoplsia free; nr: neoplasia related; wn: with neoplasia; cht: chemotherapy; rt: radiotherapy; IMS: Immunosuppression; PTLD: Post-Transplant Lymphoproliferative Disease

Table 2: Clinical characteristics of the 40 patients with de novo tumor. 
PTLD being $62 \%, 45 \%$ and $45 \%$ versus $75 \%, 62 \%$ and $62 \%$ respectively $(\mathrm{p}=0.97)$ (Figure 2$)$. The 10 -years patient survival was significantly lower (39\% versus $75 \%, \mathrm{p}=0.0047$ ) in patients who developed a de novo tumor compared to patients without de novo tumors as reported in Figure 3.

Incidences rates (IR/100.000) and SIR with 95\% CI according to cancer site/type and transplant group are shown in Table 3. Overall, the risk of cancer, excluding non-melanoma skin cancer, of these transplant recipients was 3-fold significantly higher than that of the general population of the same age and sex (95\% CI: 2.0-4.3). Cancer sites or types with significantly elevated SIR included KS (SIR=212), NHL (SIR=13.7), oesophagus ( $\mathrm{SIR}=18.7)$, melanoma ( $\mathrm{SIR}=10.1)$ and head and neck cancers (SIR=4.6) (Table 3). These findings were substantially homogeneous with regard the two groups (i.e., Padova and Udine), though the small numbers which resulted from the stratified analysis decreased the statistical power.

\section{Discussion}

As most of the problems associated with the perioperative period have been overcome, attention has focused on factors affecting longterm survival of liver transplant recipients. Causes of premature patient and graft loss include recurrent disease and complications of immunosuppression, including cardiovascular disease, renal failure and malignancy. The incidence of de novo malignancies after liver transplantation ranges from $4.5 \%$ to $12.5 \%$ [9], however, the cumulative risk for de novo malignancy has been reported to accelerate the longer the allograft recipient survives, from $20 \%$ at 10 years to $55 \%$ at 15 years [10].

In the present series we report a cumulative incidence of de novo malignancies after LT, excluding non-melanoma skin cancers, of $12.8 \%$ in two LT centers, being $8.2 \%$ in the cohort from Udine and $19 \%$ in the cohort from Padova; this difference probably reflect the longer followup in Padova where LT started in 1991 while in Udine the LT program began in 1996.

Most published reports have shown increased incidence of de novo cancers such as malignant lymphomas and cutaneous neoplasms $[11,12]$ but a decreased incidence of breast cancer [13]. We have

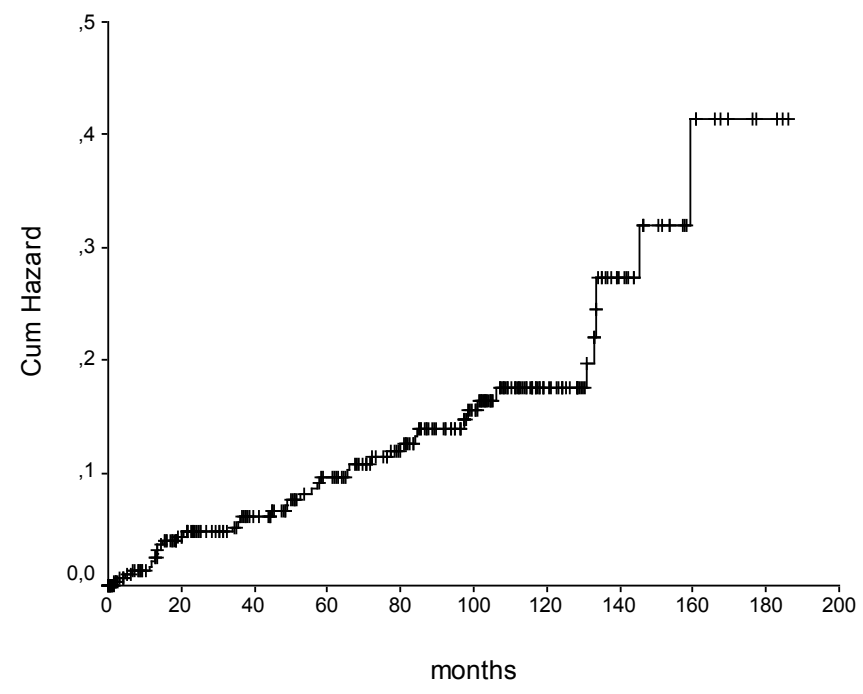

Figure 1: Risk of developing any type of de novo tumors (excluding nonmelanoma skin cancers) after liver transplantation.

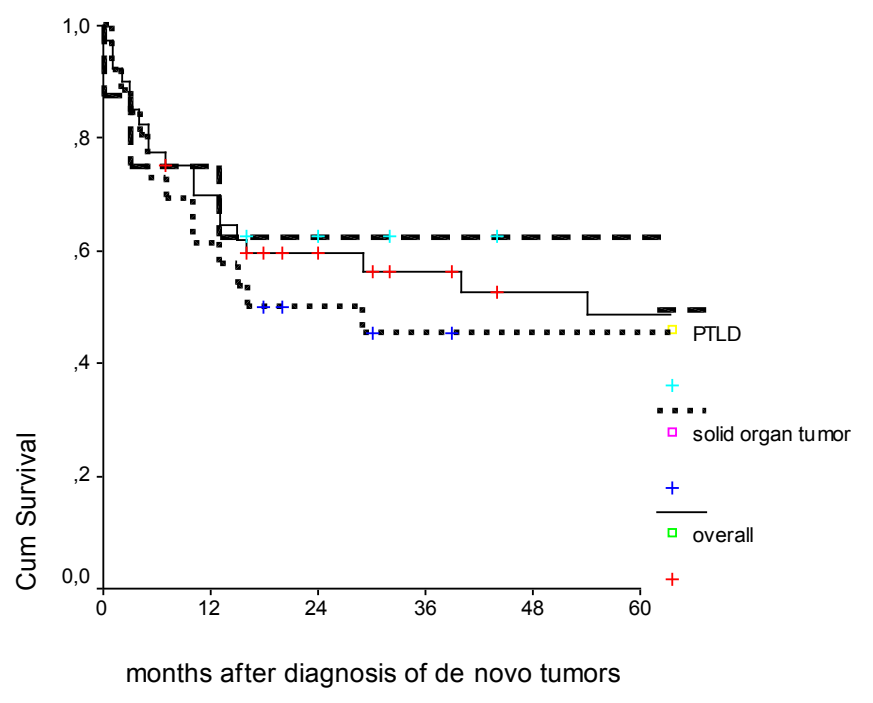

Figure 2: Overall survival of patients with diagnosis of de novo tumors, stratified then in solid organ tumors and PTLD.

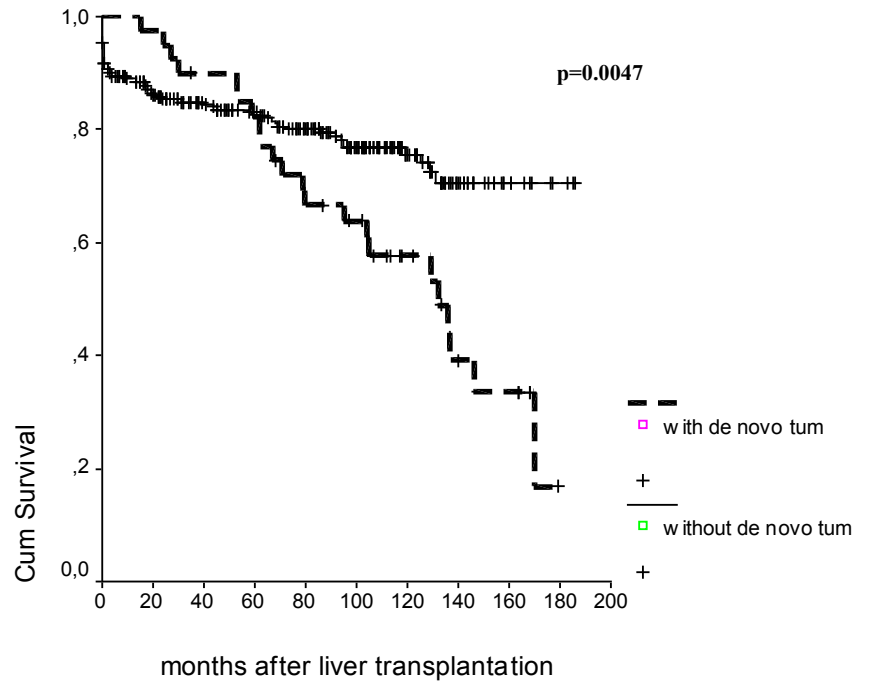

Figure 3: Survival after liver transplantation in patients with and without de novo tumors.

found increased risk of non-Hodgkin lymphoma (SIR=13.7), cancer of the oesophagus (SIR=18.7), melanoma ( $\mathrm{SIR}=10.1$ ) and head and neck neoplasm $(\mathrm{SIR}=4.6)$ but no increased risk of colon, lung and breast cancers. Overall, the risk of cancer (non-melanoma skin cancer excluded) of these transplant recipients was 3-fold significantly higher than that of the general population of the same age and sex $(95 \%$ CI:2.0-4.3).

The most common de novo tumor in our study group, as reported by others $[12,14,15]$, was PTLD accounting for $20 \%$ of all the cancers arising in our cohort, followed by tumors of the head and neck (17\%) and Kaposi sarcoma (17\%). PTLD is a significant cause of mortality in allograft recipients. Benlloch and colleagues [16] suggested that hematological appeared earlier than solid tumors, were more prevalent in those transplanted after 1995 than before and associated with a lower survival than solid organ tumors. We found that survival of lymphoid tumor was not different from that of solid organ tumors in our cohort. 


\begin{tabular}{|c|c|c|c|c|c|c|}
\hline \multirow[b]{2}{*}{$\begin{array}{l}\text { Cancer site/type } \\
\text { (ICD-10) }\end{array}$} & \multirow[b]{2}{*}{$\begin{array}{l}\text { Obs. } \\
\text { Tot. (PD/UD) }\end{array}$} & \multirow[b]{2}{*}{$\begin{array}{c}\text { IR } \\
* 100.000\end{array}$} & \multicolumn{2}{|c|}{ TOTAL } & \multirow{2}{*}{$\begin{array}{l}\text { Padova group } \\
\text { SIR }(95 \% \mathrm{CI})\end{array}$} & \multirow{2}{*}{$\begin{array}{l}\text { Udine group } \\
\text { SIR }(95 \% \mathrm{CI})\end{array}$} \\
\hline & & & SIR & $95 \% \mathrm{Cl}$ & & \\
\hline Head and neck (C00-14 and 30,32$)$ & $7(4 / 3)$ & 231.4 & 4.6 & $1.3-11.9$ & $4.4(0.5-16.1)$ & $4.8(0.6-17.5)$ \\
\hline Esophagus (C15) & $5(3 / 2)$ & 171.8 & 18.7 & $3.9-54.7$ & $12.1(0.3-67.6)$ & $25.7(3.1-92.9)$ \\
\hline Stomach (C16) & $3(2 / 1)$ & 171.3 & 4.3 & $0.9-12.6$ & $5.6(0.7-20.4)$ & $2.9(0.1-16.4)$ \\
\hline Colon (C18) & $2(2 / 0)$ & 114.9 & 2.5 & $0.3-9.2$ & $5.2(0.6-18.8)$ & NC \\
\hline Lung (C34) & $4(2 / 2)$ & 114.2 & 0.9 & $0.1-3.2$ & $0.9(0.0-4.8)$ & $0.9(0.0-5.2)$ \\
\hline Melanoma of skin (C43) & $2(1 / 1)$ & 114.4 & 10.1 & $1.2-36.3$ & $9.5(0.2-53.2)$ & $10.6(0.3-59.2)$ \\
\hline Kaposi's sarcoma (C46) & $6(6 / 0)$ & 291.5 & 211.6 & $68.7-493.8$ & $370.2(120.2-863.9)$ & NC \\
\hline Breast, female (C50) & $1(0 / 1)$ & 193.3 & 1.2 & $0.0-6.7$ & NC & $2.1(0.1-12.0)$ \\
\hline Cervix uteri (C53) & $2(2 / 0)$ & 192.8 & 12.8 & $0.3-71.4$ & $28.1(0.7-156.5)$ & NC \\
\hline Non Hodgkin's Lymphoma (C82-85,C96) & $8(3 / 5)$ & 286.7 & 13.7 & $4.5-32.0$ & $10.7(1.3-38.7)$ & $16.9(3.5-49.3)$ \\
\hline All cancers but skin & $40(25 / 15)$ & 1822.1 & 3.0 & $2.0-4.3$ & $4.0(2.4-6.2)$ & $2.1(1.1-3.8)$ \\
\hline
\end{tabular}

NC: the SIR was not computed because no cancer cases were observed

Table 3: incidences rates (IR) (*100.000) and standardized incidence ratios (SIR) with $95 \%$ confidence intervals $(\mathrm{CI})$ according to cancer site/type and transplant.

The incidence of breast cancer after transplantation does not appear to be increased as already reported in the literature [13].

The incidence of de novo cancers such as head and neck and upper gastrointestinal tumors (esophageal and gastric cancer) in which the abuse of alcohol is universally recognized as a risk factor was increased in our population of liver transplant recipients; 13 out of 15 patients (87\%) diagnosed with one the those cancers have been transplanted for alcoholic liver disease. In the non-immunosuppressed population, alcohol abuse is associated with an increased risk for several malignancies, including liver and alimentary tract $[17,18]$. It has been shown that alcohol suppresses natural killer (NK) cell activity in murine models [19]. and NK cells have an antitumor effect [20,21], and consequently the suppressive effect of alcohol on NK cells could promote tumorigenesis. However, although the Cincinnati Transplant Tumor Registry confirms no increased tumor incidence, it suggests that these common tumors tend to occur at an earlier age (mean, 41 years) in transplant recipients compared with the general population [22]. However, the mean age at tumor diagnosis in the present series was not reduced (58 years), primarily because of the older mean age (51 years) at time of liver transplantation. A 3-fold increased risk of esophageal cancer after organ transplantation has been described [23]. Patients with esophageal cancer face an additional risk due to the habit of regular alcohol consumption. The occurrence may be related to a chronic exposure of alcohol and tobacco prior to transplantation, and was shown to play a more important role. Presser et al. [24] reported on 9 patients $(0.5 \%)$ diagnosed with a de novo esophageal cancer and 1 patient with cancer of the cardia $(0.05 \%)$ out of 1,926 subjected to liver transplantation from 1988 to 2006; all those 9 patients had a pre-transplant history of alcohol abuse. The incidence of de novo esophageal cancer after LT seems to be increased in patients with alcoholic cirrhosis, but not in patients with different underlying disease. Any factor that causes chronic irritation and inflammation of the esophageal mucosa appears to increase the incidence of esophageal and gastric cancer. Immunosuppression may enhance the oncogenic effects of pre-transplantation alcohol and tobacco consumption, as well established risk factors [25]. Strategies to facilitate the early detection of de novo malignancies and to reduce the risk for those malignancies, such as cessation of smoking and alcohol consumption, are of paramount importance to reduce the impact after transplantation.

KS was rare in the United States before the advent of AIDS and is always related to HHV-8 infection in immunocompromised patients. KS has been described primarily in kidney transplant recipients of Mediterranean descent, but some cases have been reported in liver transplant recipients receiving cyclosporine or tacrolimus [26]. All our cases of KS were HHV-8 positive at time of the diagnosis; the high prevalence of KS in our population ( $\mathrm{SIR}=291.5)$ might be related to the geographical area of our patients with $46 \%$ of transplanted patients living in the Mediterranean area.

Hepatitis $\mathrm{C}$ virus (HCV) infection has been linked to increased risk of lymphoma among immunocompetent individuals [27]. Buda et al. [28] reported a higher proportion of HCV-positive patients developed PTLD than the HCV-negative cases ( $8 \%$ vs $2 \%, \mathrm{p}=0.017$ ) in recipients of cardiac transplantation. Morton and colleagues [29] in a retrospective cohort study of all individuals in the United States who received their first solid organ transplant from 1994 to 2005 using Scientific Registry of Transplant Recipients data reported that 1,630 patients were diagnosed with PTLD and HCV prevalence at transplantation was $11.3 \%$; they concluded that HCV infection did not increase PTLD risk in the total cohort. McLaughlin et al. [30] reported an increased risk for PTLD in HCV liver transplants recipients (7\%) versus HCV negative recipients $(0.8 \%, \mathrm{p}=0.02)$. In our experience all patients diagnosed with de novo post-transplant lymphoproliferative disease were $\mathrm{HCV}$ or $\mathrm{HBV}$ positive confirming a role of viral infection in PTLD development.

In conclusion based on the analysis of this cohort of 313 liver transplant recipients during a total follow-up time of 1,753 PYs we have shown that the risk of cancer of those transplant recipients was 3-fold significantly higher than that of the general population of the same age and sex. KS (SIR=212), NHL (SIR=13.7), oesophagus ( $\mathrm{SIR}=18.7)$, melanoma ( $\mathrm{SIR}=10.1)$ and head and neck cancers ( $\mathrm{SIR}=4.6)$ were the de novo malignancies more frequently encountered in this transplant cohort in comparison with the general population, while the incidences of such commonly occurring tumors as carcinomas of lung, breast, colon, and prostate are not uniformly increased across liver transplant recipients. The development of de novo post-LT malignancies in this cohort of patients is associated with lower long-term survival when compared to transplanted patients who were not diagnosed with tumors after liver transplantation, confirming that cancer is a major cause of mortality in the long term and that continuous tumor-surveillance is warranted in this immunocompromised population.

\section{References}

1. National Institutes of Health. National Institutes of Health Consensus Development Conference Statement: liver transplantation, June 20-23, 1983 Hepatology 1984; 4:107.

2. Haagsma EB, Hagens VE, Schaapveld M, van den Berg AP, de Vries EG, et 
Citation: Baccarani U, Serraino D, Adani GL, Rossetto A, Lorenzin D, et al. (2011) The Impact of De novo Tumors after Liver Transplantation on Long Term Survival. J Transplant Technol Res S1:005. doi:10.4172/2161-0991.S1-005

Page 6 of 6

al. (2001) Increased cancer risk after liver transplantation: a population-based study. J Hepatol 34:84-91.

3. Buell JF, Gross TG, Woodle ES (2005) Malignancy after Transplantation. Transplantation 80:S254-S264.

4. Penn I (1998) Occurrence of cancers in immunosuppressed organ transplant recipients. Clin Transplant 147-158.

5. Buell J, Hanaway M, Thomas M, et al. (2004) Malignancies associated with liver transplantation. In: Busuttil RW, Klintmalm GB, ed. Transplantation of the liver. Philadelphia: W.B. Saunders.

6. Fung JJ, Jain A, Kwak EJ, Kusne S, Dvorchik I, et al. (2001) De novo malignancies after liver transplantation: a major cause of late death. Liver Transpl 7: S109-S118.

7. Parkin DM, Whelan SL, Ferlay J, Raymond L, Young Y (1997) Cancer Incidence in Five Continents, Vol. VII. IARC Sci Publ 19:1261-1263.

8. Breslow NE, Day NE (1987) Statistical methods in cancer research.Vol. II-The design and analysis of cohort studies. IARC Sci Publ 82:1-406.

9. Saigal S, Norris S, Muiesan P, Rela M, Heaton N, et al. (2002) Evidence of differential risk for posttransplantation malignancy based on pretransplantation cause in patients undergoing liver transplantation. Liver Transpl 8:482-487.

10. Haagsma EB, Hagens VE, Schaapveld M, van den Berg AP, de Vries EG, et al. (2001) Increased cancer risk after liver transplantation: A population-based study. J Hepatol 34:84-91.

11. Oo YH, Gunson BK, Lancashire RJ, Cheng KK, Neuberger JM (2005) Incidence of cancers following orthotopic liver transplantation in a single center: comparison with national cancer incidence rates for England and Wales. Transplantation 80:759-764.

12. Sanchez EQ, Marubashi S, Jung G, Levy MF, Goldstein RM, et al. (2002) De novo tumors after liver transplantation: a single-institution experience. Liver Transpl 8:285-291.

13. Jain AB, Yee LD, Nalesnik MA, Youk A, Marsh G, et al. (1998) Comparative incidence of de novo nonlymphoid malignancies after liver transplantation under tacrolimus using surveillance epidemiologic end result data. Transplantation 66:1193-1200

14. Frezza EE, Fung JJ, van Thiel DH (1997) Non-lymphoid cancer after liver transplantation. Hepatogastroenterology 44:1172-1181.

15. Xiol X, Guardiola J, Menendez S, Lama C, Figueras J, et al. (2001) Risk factors for development of de novo neoplasia after liver transplantation. Liver Transpl 7:971-975
16. Benlloch S, Berenguer M, Prieto M, Moreno R, San Juan F, et al. (2004) De novo internal neoplasms after liver transplantation: increased risk and aggressive behavior in recent years? Am J Transplant 4:596-604

17. Watson RR (1988) Ethanol, immunomodulation and cancer. Prog Food Nutr Sci 12:189-209.

18. Roselle G, Mendenhall CL, Grossman CJ. Effects of alcohol on immunity and cancer. In: Yirmiya R, Taylor AN (eds). Alcohol, immunity, and cancer. Boca Raton, FL: CRC, 1993:3.

19. Ben-Eliyahu S, Page GG, Yirmiya R, Taylor AN (1996) Acute alcohol intoxication suppresses natural killer cell activity and promotes tumor metastasis. Nat Med 2:457-460.

20. Lotzova E (1993) Definition and functions of natural killer cells. Nat Immun 12:169-176.

21. Mather GG, Talcott PA, Exon JH (1994) Characterisation of a chemically induced tumor model and the effects of natural killer cell depletion by antisialo GM-1. Immunobiology 190:333-345.

22. Penn I (1991) Cancer in the immunosuppressed organ recipient. Transplant Proc 23:1771-1772.

23. Adami J, Gäbel H, Lindelöf B, Ekström K, Rydh B, et al. (2003) Cancer risk following organ transplantation: a nationwide cohort study in Sweden. $\mathrm{Br}$ Cancer 89:1221-1227.

24. Presser SJ, Schumacher G, Neuhaus R, Thuss-Patience P, Stieler J, et al (2007) De novo esophageal neoplasia after liver transplantation. Liver Transpl $13: 443-450$.

25. Yu MC, Garabrant DH, Peters JM, Mack TM (1988) Tobacco, alcohol, diet, occupation, and carcinoma of the esophagus. Cancer Res 48:3843-3848.

26. Kusne S, Blair JE (2006) Viral and fungal infections after liver transplantationpart II. Liver Transpl 12:2-11.

27. Viswanatha DS, Dogan A (2007) Hepatitis C virus and lymphoma. J Clin Patho 60:1378-1383.

28. Buda A, Caforio A, Calabrese F, Fagiuoli S, Pevere S, et al. (2000) Lymphoproliferative disorders in heart transplant recipients: role of hepatitis $C$ virus (HCV) and Epstein-Barr virus (EBV) infection. Transpl Int 13:S402-S405.

29. Morton LM, Landgren O, Chatterjee N, Castenson D, Parsons R, et al. (2007) Hepatitis $\mathrm{C}$ virus infection and risk of posttransplantation lymphoproliferative disorder among solid organ transplant recipients. Blood 110:4599-4605.

30. McLaughlin K, Wajstaub S, Marotta P, Adams P, Grant DR, et al. (2000) Increased risk for posttransplant lymphoproliferative disease in recipients of liver transplants with hepatitis C. Liver Transpl 6:570-574.
This article was originally published in a special issue, Post-Transplantation Disorders handled by Editor(s). Dr. Piergiorgio Messa, IRCCS Fondazione Ca' Granda, Italy; Dr. Cheguevara I Afaneh, Weill Cornell Medical College, USA; Dr. Shaoyan Hu, The Children's Hospital of Soochow University, China 